\title{
The Case of the 'Nasty Trolley' or How Mobile Learning and Tablets are Influencing Emotions and Affects and Shaping the Constitution of the Identity of Teachers and Students
}

\section{Paula Lameu ${ }^{1}$ (D)}

Published online: 3 June 2019

(C) The Author(s) 2019

\begin{abstract}
The purpose of this study was to discuss the influence of the use of tablets and mobile learning in post-secondary education and their impact on the emotions and affects felt by a teacher and students and on their identity constitution. Assemblage theory was the ontoepistemological perspective in which this investigation was grounded, and assemblage ethnography was the methodology used to collect data. An ethnographic account was provided based on what was observed during lessons, and was analysed using the concepts of emotions, affects and subjectivation. Findings indicated that no contradictory emotions and affects emerged as a result of the actions and interactions of components in the assemblage. There was a smooth relationship among human components, influencing the way they see each other and their roles. However, regarding human and non-human components, the affects and emotions that emerged impacted each other, causing tensions between these components.
\end{abstract}

Keywords Mobile learning $\cdot$ Tablets $\cdot$ Subjectivation $\cdot$ Affects $\cdot$ Emotions $\cdot$ Assemblage

\section{Introduction: The Case of the Nasty Trolley}

When I arrived in the room of Miss Mills, the history teacher, she greeted me with a smile. She apologised for the inconvenience of not having the classes in the 6th form building. She said that they were going to use tablets for research and it was really difficult for her to transport the tablets' carrying case. Miss started the class talking about the field trip they would have to Auschwitz during the next half-term. While she was explaining how things would work, I started thinking about her carrying that massive tablet trolley.

Paula Lameu

paula@tecacademy.com.br

1 Department of Education and Social Justice, University of Birmingham, Edgbaston Park Road, Birmingham B15 2TT, UK 
She was a short lady. She was probably in her 50s. With her short red hair and her reading glasses on a leather neck strap cord, she reminded me of those lovely ladies we expect to find in museums or libraries. She spoke with a soft, low voice as if she was lullabying a baby. I felt comforted, even with the talk of such a disturbing topic. Then, I imagined that lovely lady, who could be my aunt, carrying that gigantic case of tablets. The trolley had space for 25 iPads. There was also a charger to which the iPads were connected when they were not in use. I had no idea how heavy it was. What I knew was that I was not able to carry that thing and unless that lovely lady had superpowers she would not be able to manage it either. The trolley had wheels, but they were not sufficient to be able to move around the building with 'that thing'. Miss Mills' room was on the first floor of the school. The building was too old to have an accessible ramp and of course, it did not have a lift. She was supposed to carry 'that thing' up and down at least two flights of stairs. She could have asked someone to carry 'that thing' for her but it would be her responsibility and someone else's if something happened to 'it'. It was safer to have 'that thing' in her room.

Students stood up to help themselves to the tablets in the trolley. She explained the task: in pairs, students would search for something on the internet. Today, they only needed to collect information. There was no need for presentations. She gave them small papers with some instructions because each pair was going to look for something different. She said they could copy the information onto sheets of paper or print it via the iPad if they knew how to do it. She also said they were allowed to help each other and even come up with alternative ways of registering information. She showed them where to find extra material in her room: highlighters, markers, cardboard and white sheets of paper. They could use anything they wanted.

One student got an iPad and pretended it was a pillow. 'It's so warm,' he said, whilst laying his head on the back of the iPad. Half of the class changed the way they were sitting after picking up the iPads. Students crossed their legs in an informal way, not placing the iPads on the table, but on their laps. They seemed to be more relaxed.

The teacher started walking around the room to check how the work was progressing. No student asked for help to find information. Some were copying the information on white sheets of paper, others were making notes on colourful cardboard. She stopped by a group and one student explained he was copying and pasting the information on a file in Google Docs. He and his peer were doing the activity at the same time, independently, looking for different sources, and when they found something interesting, they were copying, pasting and editing the same shared file. 'That's brilliant!' said the lovely lady with a smile. She went back to her table.

On the other side of the room, one student at the front asked how those students at the back were doing that. The other student said they would need to use a Google account, $\log$ in and upload a file in Google Drive; then they could share the document. The student who asked seemed to be upset and frowned. He said he did not have a Google account. All students who had stopped to listen returned to their tasks. Some continued copying onto pieces of paper, others copied and pasted in a Word processing file, and another said he was going to send himself the information via e-mail. Some seemed to like this idea: they nodded and smiled, indicating they would do the same.

Most of the students were talking while doing the activity. There was a pair at the front doing something suspicious. They were trying to hide their tablets, with sneaky smiles on their faces. A student seemed to have activated 'Siri'. Miss listened to it and said 'Oops' with a lovely smile. The boys looked at each other, left Siri to the side, and con- 
tinued searching. One student in this group at the centre got out his mobile and started looking at something. The other three boys who were near him got out their phones as well. They were looking for something independently, but they were comparing something. I was wondering if they were still searching for the information the teacher asked them to. Then, based on what the group started discussing, it became clear they were trying to make a Google account and download Google Drive to the tablets. Another student told them, 'you need to have an iTunes account as well'. The group complained, huffed and put their mobiles back in their backpacks. They went back to their iPads. Their enthusiasm disappeared.

Another boy in the middle of the room started taking funny pictures with the iPad. $\mathrm{He}$ was making faces, taking the pictures and showing them to his friends, who were laughing. Miss raised her head again and asked, 'What are you doing?' with an impish smile, indicating she knew exactly what they were doing. Another boy from the group smiled back, looked at his feet and answered, 'Sorry, Miss'. Then they returned to their tasks. One student at the back asked Miss if the task had to be finished that day. She said there was no need, as they would talk about it the following day. Students seemed to be more relaxed and they raised their voices a little while talking.

The teacher stood up and walked around the room to check how far they had gone. She announced they would have 30 more minutes to finish the task, in the next class. It was five minutes till the end of the lesson and some students started playing on the iPads. The bell rang and the teacher announced, 'Wrap it up'. The students turned the iPads off and some collected them up carefully to put them back in the trolley.

Information and Communication Technology (ICT) is part of ordinary tasks: organising the appointment book, making the grocery list, and taking pictures, to mention some. It would be natural that gadgets and practices that are part of everyday life were used in lessons. However, when referring to ICT, it is necessary to address its multiplicity and complexity. It is multifarious because it involves: theory, practice, hardware, software, and infrastructure. It is complex because it demands specific conditions to be used in schools, for example policy, curriculum, budget and pedagogy. Although these elements are independent of ICT, they directly influence how ICT is used in educational settings. In order to engage with questions of how ICT impacts different situations in classrooms; how lessons take an unexpected direction; and why people still judge ICT as being "bad" or "good", as if ICT had an "evil force" to ruin the teachers' plans, this study is part of a broad study in which ICT was investigated in its complexity and multiplicity. Assemblage theory was the onto-epistemological perspective that guided the study and assemblage ethnography was the methodology used to collect data.

This lesson was observed in a post-secondary school in the UK. The purpose of observing this lesson was to see the everyday use of tablets and their relationship to mobile learning. This relationship seems to be taken for granted by some scholars and practitioners, as if one implies the other. This fact seemed to influence the way the teacher felt about her practice because the students' actions might not have been 'mobile enough'. This problem is part of the discussion about what constitutes mobile learning.

\section{Mobile Learning and the Use of Tablets}

Mobile learning (or m-learning) has been one of the key current trends of educational applications for new technologies (Wu et al. 2012; Camilleri and Camilleri 2017; Chiang et al. 2016). It has been described as 'the process of learning mediated by a mobile 
device' (Kearney et al. 2012, p. 2), enabling students to engage in tasks without being 'tightly delimited' to a physical location (Kukulska-Hulme 2005). For Vavoula et al. (2004), when a learner takes advantage of learning opportunities offered by mobile technology this can also be considered m-learning, and it does not necessarily imply the state of being in motion.

M-learning is also considered to enhance and promote: new ways of learning (Furió et al. 2015); collaboration, access to information and deeper contextualisation of learning (Koole 2009); portability, social interactivity, context sensitivity, connectivity and individuality (Klopfer et al. 2002); an authentic learning environment (Boticki et al. 2015) and learners' engagement ( $\mathrm{Lu}$ et al. 2014), presence (awareness of their location), interest to accomplish tasks (Gerger 2014) and flexibility (Danaher et al. 2009). Pachler et al. (2010) claimed that m-learning brings a 'mobile complex' composed of the interrelationship of learners with structures, agency and cultural practices. For Traxler (2009), m-learning results in a 'noisy' and 'problematic' environment in which the personal, the contextual and the situated are considered.

Most studies on m-learning focus on its effectiveness (Wu et al. 2012) or on the affordances of the tools (Traxler 2007). According to Wu et al. (2012), 86\% of the studies reviewed in their meta-analysis showed positive results regarding its effectiveness. $4 \%$ of the studies reported a neutral outcome and $1 \%$ a negative outcome. In formal educational contexts, higher education is the level at which m-learning is used the most, followed by elementary schools (or primary schools in the UK). Post-secondary and secondary schools use m-learning the least. In addition, argues Traxler (2007), rather than focusing on the tools, studies should examine pedagogies suitable for m-learning and investigate it from the perspective of the learner. For him, this change in perspective would allow rethinking from the students' point of view.

Domingo and Gargante (2016) focused on the teachers' perceptions of mobile technology learning impacts and applications' use in the classroom. In their review they identified that teachers' perceptions focused on five different kinds of impacts of mobile technology in learning: providing new ways to learn, increasing engagement to learning, fostering autonomous learning, facilitating access to information, and promoting collaborative learning. They also identified some relevant affordances of mobile technologies and some applications (apps): portability, interactivity, context sensitivity, connectivity, individuality and social media.

One challenge in developing studies about mobile technologies is that new gadgets have been emerging fast. Tablets have been associated with mobile learning, and Wu et al. (2012) did not include these gadgets in their descriptions. This might be because their use is too recent for studies about them to be available. Research into the use of mobile devices is still in its infancy.

Haßler et al. (2016) have challenged the idea that the fragmented nature of the current knowledge base and the scarcity of rigorous studies make it difficult to draw firm conclusions about how tablets can viably support children in completing different learning tasks. On the contrary, they claim that there is a reasonable amount of research investigating the impact of the use of tablets regarding the knowledge and skills of school-age students.

Haßler et al. (2016) raised some issues which strongly influence the use of tablets. The fact that the choice of mobile devices is constrained by what is commercially available and financially feasible directly impacts the decisions of schools implementing their use. The authors believe that the development of rigorous contingency plans is necessary for school-based tablet projects. This is because educational technologies are most effective 
when there is an orchestrated strategy to investigate digital and non-digital resources. As a result, they allege that learning is improved when the school's infrastructure facilitates the use of this technology.

Schools have assumed that teaching staff are prepared to use tablets. However, this is not what has been seen, according to Haßler et al. (2016). As technology changes rapidly, teaching staff are always in need of professional development. A third issue was that established pedagogy also did not necessarily change with the introduction of new technologies. This is because there is a tendency for teachers to use technology to reproduce traditional ways of teaching. In order to help staff, proper support, relevant training and a tablet policy could stimulate the use of tablets on a regular basis.

Bannan et al. (2016) argue that even research needs to be different in mobile contexts. From the perspective that mobile technology can enhance learning, they state that it requires an "increase to sensitivity to context, cultural resources, social-cultural features of formal and informal learning environments and the reconceptualization of research approaches that align with these important and unique factors" (p. 02). Building on Sharples et al. (2009), they suggest that mobile learning presents significant challenges for evaluation, as the content may not be fixed and the activity can cut across formal and informal settings. This transference across content, location and mobile learning emphasizes that there is no fixed point to locate an observer, the learning may be spread across locations and times, and interrelated with other activities, to mention just a few issues (Bannan et al. 2016).

Literature has shown the complexity involved in the use of tablets. This study is interested in exploring this complexity by asking different question regarding emotions, affects and the constitution of the identity of subjects involved in the schooling process. In order to do that, an onto-epistemological perspective was needed, which opened up the possibility of using different analytical tools to observe and discuss what happened in the classroom and the implications of the use of tablets in education.

\section{Assemblage Theory}

With the purpose of looking at the complexity of the classroom environment in which tablets were in use, this study was grounded on assemblage theory. According to DeLanda (2006), this 'approach to social ontology' regards assemblages as 'wholes constructed from heterogeneous parts' (p. 03). For him, these parts are social entities produced by historical processes. These entities can be characterised not only by their properties but also by their capacities. However, these social entities are not just humans but include other things that might be implicated, in our case, in classroom practices: furniture, ICT, curriculum, timetables, policies, etc.

For Youdell (2011), the idea of assemblages is helpful in conceptualising 'the complex terrain of education and the ways that economy and politics, policy, subjectivities, pedagogy, everyday practices, and feelings come together to form the education assemblage' ( $\mathrm{p}$. 14). Youdell (2011) believed that in order to understand how these entities or 'components' (Youdell, after Deleuze and Guattari 1984, 1987) come together, it is necessary to map them in a particular assemblage. But this map should not be based on the presence of the components in an assemblage but on their productivity. 
As suggested by DeLanda (2006), the point of using assemblage theory is to look at processes of production rather than the list of properties of components or the finished product. It is believed that ICT, as a component of the assemblage, has productive forces which influence the constitution of the identity of teachers and students, the way they feel and the way spaces are composed, to take some examples.

The intention of this study was not to look at all the aspects and components of the education assemblage. This would not be possible due to space limitations and it has already been done elsewhere (Lameu 2017). The aim of the broad study was to identify what ICT meant in the schooling process and its productive forces in the assemblage. The purpose of this study is to discuss the productive forces of three components of the assemblage identified in the anecdote: emotions, affects and subjectivation of teachers and students. The framework used to analyse the anecdote is based on the analytical framework provided by Kraftl (2013, 2015a, b) and Youdell (2011) as follow.

\section{Emotions and Affects}

When dealing with children and young people, it is necessary to consider their emotions, advocated Kraftl (2015a, b). According to him, emotions 'make spaces' because they constitute and are constituted by a range of scales, places, geographical contexts, mobilities and boundaries (Blazek and Kraftl 2015). In other words, the space in which people are situated influences how they feel, and the way they feel in these spaces also influences its constitution. From Kraftl's point of view, childhood is not only a social construction but also a spatial one, in which emotions have a crucial role. The ways children (and young people) sense a space establishes an iterative relationship between their emotional development and their sensing of physical spaces. For Kraftl (Blazek and Kraftl 2015), the material constitution of spaces evokes particular kinds of atmosphere, for different purposes.

However, Kraftl pointed to the fact that some spaces are designed and thought up to make people feel in pre-determined ways and not in other ways (Kraftl and Adey 2008). According to him, sometimes this is achieved and sometimes it is not. It was suggested that, even if space is designed to make some perceptions emerge, there is no guarantee they are going to happen, because other perceptions and emotions might emerge. Kraftl explained this through the concept of affect. It is an ability to affect and be affected, being a prepersonal intensity corresponding to 'the passage from one experiential state of the body to another' (Massumi 1987, p. v). This means that different bodies have the capacity to affect other bodies and all bodies can be affected by other bodies. Massumi also stated that this process also implies an 'augmentation or diminution in that body's capacity to act' ( $\mathrm{p}$. xvii). What he is saying is that the actions of bodies, or components for this study, might act more or less regarding the action of other components upon them. The fact that all components have the capacity to act, not only people, enables the reflection on this capacity of things to act, for example, ICT, and to ask questions about the extent to which the actions of teachers and students are increased or diminished due to ICT.

Kraftl (2015a) emphasised the difference between emotions and affect. For him, emotions are characterised by 'how an individual feels' (p. 49), of which happiness, joy and fear are some examples. On the other hand, affects are difficult to name and they do not correspond to a single emotion. While emotions refer to the individual, affects refer to the collective as modes of feelings 'sometimes understood as atmospheres or temporary sparks of connectedness (...) are shared' (p. 49). According to Kraftl (2015a): 
... affects are multiple, extensive and distributed. Emotions may be directed outward, as for instance, as individual projects fear onto a dark alley in a city; but emotions tend to be located within the cognitive process of an individual agents. Affects, rather, begin in the interstitial space between agents - agents who may, incidentally, be human or non-human - and, therefore are constitutive of the very lively but the evasive forces that characterise non-representational notions of spatiality. (p. 50)

Kraftl (2015a) believed that considering emotions is important because they might shape spaces of professional practice: emotions emerge at the entanglements of the structural organisation of practitioners' work and their embodied experiences with clients. This suggests that the actions of teachers and students in classrooms, and how they feel about their actions and about each other's actions, are going to affect the way lessons are shaped. At the same time, students and teachers are going to feel the action of the components of the classroom (and policies, and curriculum, and furniture...) on their bodies, and they will act in relation to what and how they feel.

Looking at emotions in the study enables the researcher to engage with questions of how people feel in relation to each other and in relation to other components in the assemblage. Looking at collective modes of feelings would enable the researcher to reflect on the forces that emerge in the space between components and what is produced by it.

\section{Subjects and Identity Constitution}

Subjectivation is the process in which human beings are made subjects (Foucault 1982). He identified three modes of objectification which transform human beings into subjects. The first mode of inquiry is an attempt to give the subjects themselves the status of science. The second mode is by objectivizing the subject in what he called "dividing practices" (Foucault 1982, p. 208) in which subjects are classified and divided as "good" or "bad". The third mode refers to how the subject turns himself/herself into subject, by being recognised as subjects of a specific theme.

Butler (1997) stated that subjectivation is "the process of becoming subordinated by power as well as the process of becoming a subject" (p. 02). This power is both external and internal to the subject. It is external because the practices to be developed and the arrangement subordinate the subject, constituting one's identity. It is internal because the subject, once inside the system, is going to perform activities and will be vigilant to not deviate from the correct behaviour and production to be identified as such subject (Butler 1997).

From an assemblage perspective, the power mentioned by Butler (1997) comes from different components: policy, pedagogy, money, ICT gadgets, discourses, and many other elements which will specify what teachers and students might do in order to be identified as teachers and students. In addition, teachers and students will perform specific activities to recognise themselves as acting accordingly.

Deborah Youdell claimed that the schooling process makes particular sorts of people. By people, she referred to teachers and students that are constituted as subjects through everyday practices inside schools. For her, subjectivation is what 'makes us subjects' (Youdell 2011, p. 27). She believed this process is a constraining condition and that it happens via two main factors: the discourses in which people are immersed and the categorisation used to identify people. Echoing Butler, she believed that identities are constituted by a set of practices. These practices determine how people are perceived and located in 
particular categorical identities. Youdell's concern was with how categories themselves are constituted, how they relate to each other, how these constitutions are made in hierarchical relations, and how these relations are implicated in creating intersecting inequalities.

As pointed out by Youdell (2011), hierarchical binaries are perceptible in constructions of identity: man/woman, white/black, hetero-/homo- and so on. Identity categories are axes of domination/subordination in which subjects are made, and it would be no different for the binary teacher/student. Youdell (2011) argued that the problematics of these binaries are the key to critiquing identity formation and the usefulness of other categories that are created to reinforce the basic binary, such as teacher and student, and for example 'good' teacher/'bad' teacher. However, the constitution of these identities is not flat. It is suggested by the literature used by Youdell (2011) that a person is made up of a collection of identity categories or identities. The problem inherent in considering a multiple identity approach to a subject is that it does not enable the researcher to investigate the nature of the connections between these categories. It also does not allow the understanding of the subject about whom these identity categories speak, argued Youdell (2011). Nevertheless, they are still important to the constitution of teacher and student in the schooling process. Subjectivities are established and foreclosed at/by the intersections and interactions of identities.

The concept of performatives from Butler (1997) can be used to explain how people become subjects. It is argued that subjects are made through their deployment in the classificatory systems, categories and names that are used to designate, differentiate and sort people. Youdell (2011) explained that in order for performatives to work in subjectivation, they need to be recognisable in the discourses that are circulating in the settings and moments in which they are deployed. In other words, what teachers and students do in schools should be associated to what is said about them. If their actions do not make sense, 'subjectivations will fail' (Youdell 2011, p. 42).

Notions of subjectivation, the performative constitution of the subject and the question of intelligibility help us to understand the nature of the subject, the limits of 'who' this subject might be and the constraints and disavowals that are intrinsic to particular subject positions. This study does not intend to look at the discourses in which students and teachers are immersed. The importance of discourse in the subjectivation process is recognised by the researcher and already discussed elsewhere (Lameu 2017). It does not diminish the quality, rigour and depth of the discussion; it just directs it more towards specific purposes and issues.

Based on the analytical framework, the research questions this study aims to answer are:

- How do people feel using ICT in the classroom? Do these emotions differ across the teacher and the students? If yes, under which circumstances do they differ? If not, why not? How do these emotions influence decisions regarding the use of ICT in lessons?

- How are teachers' and students' identities constituted in lessons in which ICT is in use? What is the influence of emotions in the subjectivation process?

\section{Research Design and Method}

This study is part of a multiple case study regarding the use of ICT in education. The main purpose of the study was to identify what ICT meant in the schooling process and its productive forces in the assemblage. It was composed of five case studies. One primary, 
one secondary and one post-secondary school were investigated, and some technological themes were chosen to make the 'cases'.

Assemblage ethnography (Youdell 2015; Youdell and McGimpsey 2015) was the research method chosen, as it was based on assemblage theory. It considers economic, structural, spatial, temporal, representational, discursive, relational, subjective and affective relations as components of the assemblage (Youdell and McGimpsey 2015). It combines ethnographic principles to 'observe' the manifoldness of reality: human and nonhuman elements acting, reacting and interacting with each other. The focus is the actions and interconnectedness of feelings, everyday practices, pedagogies, subjects, money, political orientations, media, policy, institutional arrangement and informal knowledges (Youdell 2015).

With this in mind, a protocol of data collection was composed of multiple strategies and tools. Data were obtained via observations, interviews, document analysis, news and social media posts tracking and analysis. Observations of every lesson in each school were documented in a field diary and in a reflective diary, respectively. The former was used to describe what was observed in a descriptive way. The latter was used by the researcher to write all her impressions, questions, reflections, and feelings about what was witnessed. The purpose of having these two documents was not to separate objectivity from subjectivity in the notes of the researcher, which is not possible (Hegelund 2005). It was to have two different sources of data which the researcher could look into. Teachers, students, parents/ guardians, IT developers, head teachers, policy makers, Ofsted inspectors, ICT experts and influencers, professors and government representatives were interviewed with a semi-structured questionnaire. A list of 116 documents was analysed and the news and posts in social media from 2014 to 2016 were searched and mapped.

Data collected were anonymised before analysis. The first round of coding data was done searching for the themes: emotions, affects, subjectivation and identity. After identifying these themes. A second round of coding happened, by identifying subthemes related to ICT. These subthemes were: mobile learning, cyberbullying, gamification and personal response systems or clickers, computing and computational thinking, learning spaces and virtual learning environments. Each subtheme was chosen to become one case study that composed the broad study. From these themes, the ethnographic account of mobile learning was chosen according to be the topic of this study, by following the criteria of: representing an ordinary lesson; the subject taught should be recognisable by the readers; ICT should be one of the components of the account, independently of whether it was in use or not. The research questions were used to guide the findings in relation to the coded data with the framework proposed by Kraftl (2015a, b) and Youdell (2011) in order to identify their relationship.

\section{Findings}

After selecting the account, the findings were organised in two sections to demonstrate how the answers to the research questions emerged. Although they are presented separately, they did not have clear boundaries. On the contrary, affects, emotions, subjectivation and identity were entangled. This entanglement is discussed in the last section. 


\section{Feelings, Emotions, Affects and their Influence in the Decisions Regarding the Use of ICT}

Some emotions and affects emerged as a result of the action of components acting upon others. Although they differed regarding the source of the component, the relationship between the teacher and students was smooth (Kraftl 2015a).

Miss Mills' body and identity made the researcher and the students feel comforted, cosy and safe as if they were being lulled. Her tone of voice and her appearance made the researcher associate her with the idea of lovely ladies in whom she could trust. It was not possible to say all students were affected in the same way as the researcher. Each component reacts differently to affects, and human components are influenced by their experiences and emotions (Kraftl 2015a). However, the fact that one student pretended the tablet was a pillow confirmed that they felt they were being lulled as well. That student could have felt nothing when he got the tablet, having no response to it. On the other hand, his reaction from the flow of affects from the teacher and the tablet resulted in his feeling more comforted, laying his head on it.

These flows of affects contributed to the environment being calm and relaxed before the start of the task (Kraftl 2015a). When the teacher explained what students were supposed to do, the relaxation increased as students got the tablets. Moving from the conventional position occupied by students at their desks, they crossed their legs, placed the tablets on their laps, turned to the side, turned around and started talking while performing the activity. This relaxation would not be visible if students were not feeling this way. It was the force of the tablets acting on the students and on the teacher, and it might not happen in a different lesson without the tablets, as they might not be components of the assemblage (DeLanda 2006).

Their relaxation turned to confidence and trust as they recognised these flows of affects coming from the teacher. The student-centred approach adopted by the teacher seemed to make them feel independent, respected and mature enough to make judgements about the task and how to perform it. When the teacher chose to have a studentcentred approach, she transferred to the students the responsibility for their learning process. Their engagement came as a consequence of accepting the task and their bodies showed it, behaving in specific ways (Lu et al. 2014; Klopfer et al. 2002).

Students also seemed to feel supported by the teacher, who offered her help regarding the content. She also encouraged them to use their ICT knowledge and skills to enhance their experience, making it more convenient and effective for them in relation to the tools chosen. Students seemed to be accepted, and this influenced the way they treated each other. It might be that they felt respected by her and in return, they respected her and respected each other: the former was identified when she signposted their deviation from the activity and they promptly accepted it and returned to the lesson; the latter was the emergence of collaboration among themselves. There was no need for students to help each other during the task. The teacher said they could do it and also use any tool that best suited their needs to register information. They did not need to, but they chose to help each other and collaborate in their development of ICT skills (Koole 2009).

The affordances of the tool seemed to be recognised by students because they used them and showed others how to improve their practice. It was also their choice to use them (Koole 2009). Their choice of not insisting on learning how to copy information and choosing other ways (the conventional one on paper or sending the information via e-mail) to perform the task demonstrated how mature they were to recognise what 
would be best for them, being practical and not affecting their performance of the task (Gerger 2014).

Some students demonstrated that they were excited about the fact they could learn something different to be done with the iPads to enhance their performance. It would not affect the outcome of the task itself, but would improve their ICT skills, enhancing their knowledge about their performance. Enthusiasm was noticed in students who tried a different approach (Gerger 2014). Their bodies were inclined over the tablets, they were talking with motivation about how to tackle this situation. They appeared disappointed by the fact that it was more complicated than they realised. However, with a different idea and solution pointed out by another student, they regained enthusiasm and chose a different way to register the information, by sending it to themselves via e-mail (Danaher et al. 2009).

There was space for other emotions and affects. Students were allowed to feel like young people by playing, talking, taking funny pictures, doing something suspicious, and getting distracted by other things. Miss Mills accepted that behaviour and had fun with it. The way she reacted when students were getting distracted by other things and deviating from the task suggested she was not disapproving of them. On the contrary, her smiles, expressions and questions indicated that she considered the students' behaviour acceptable and just pointed out they still had a task to be done. Some of them seemed to feel a little bit guilty about being caught and returned to the task. This might be because they thought it indicated a lack of respect for the teacher.

Based on the flow of affects in the account, it seemed to be a productive environment, filled with positive emotions. However, there was one fact that was negative. There were some negative aspects in the reason the lesson had changed place: the fact that Miss Mills was not capable of carrying the tablet trolley.

It seemed Miss Mills felt bad, ashamed and guilty because she did not have the capacity to let the tablets be as mobile as they were supposed to. The case had wheels, emphasising the idea that they were supposed to go where students would be. She was contradicting the basic idea of using tablets when students had to move. This suggested that mobile learning would not happen, as there was 'no mobility' regarding the tools. Those students were also supposed to be in the 6th form building, having history lessons there. She knew that and that was why she was apologetic at the beginning of the lesson. It was as if she was apologising for having a body composition that did not allow her to carry that trolley. It also implied another type of apology referring to whom she was.

This made the researcher feel bad for her: upset, thinking about how that situation was unfair. Negative emotions emerged from the researcher towards the tablet trolley. She started calling the trolley 'the thing,' addressing all the damage it could do to the teacher. It was as if the carrying case was not treating Miss Mills well, leading to an unfair situation. That 'lovely lady' could be regarded as incapable or even incompetent because she was not carrying the trolley around. However, these emotions and affects were not a result of the affective flow from the tablet trolley alone. It was also an effect of the affective flow of the building, the mobile learning discourse and the school policy and regulations (Blazek and Kraftl 2015). The way the main building was constructed did not enable the mobility of the trolley, according to the teacher's needs (Haßler et al. 2016). 


\section{ICT, Emotions and Affects in the Identity Constitution and Subjectivation Process}

The teacher and the students were the two main types of subjects in this account. They had a peculiar relationship in this environment not only because of the use of tablets but because of the teacher's identity. The teacher in this account was presented with a peculiar identity. She had a name-Miss Mills-and her hair, choice of clothes, type of glasses, the colour of her hair and haircut, the tone of her voice, her age, gender, weight and height were clues of who she was (Youdell 2011). All these elements and her smiles contributed to the composition of an easy, likeable woman. It was the first time the researcher saw and talked to her. The fact that she was considered a 'lovely lady' demonstrated how these physical elements articulated her constitution of identity. This was the first impression of the researcher, which was consolidated over the lesson.

The way Miss Mills acted (Butler 1999) inspired comfort and safety when she was speaking, addressed in the account by the impression of being lulled. This impression was shared by students and evidenced when one got a warm tablet and pretended it was a pillow, as an immediate reaction to being lulled. That student was just completing the act of being lulled and adding comfort to his experience in that room.

In addition to that warm, cosy and safe place, Miss Mills built a supportive and trustworthy environment (Youdell 2011). She planned a lesson in which tablets were used in a student-centred approach, and the students would have the responsibility of dealing with the iPads. The task was simple, just demanding a basic knowledge of locating the web browser in the iPad and using search engines. The students were regarded as independent because they were supposed to work in pairs, researching different contents. They were regarded as autonomous because they could make their own decisions on how to split the tasks, which sources to search, which information to copy and where and how to store the information collected. She also offered her help on the content to students in need and allowed them to help each other in relation to different needs. By doing this, she implied she was confident in their capacities and respected them as individuals. They were allowed to have different knowledge and they would not be judged or ranked by her for it.

Miss Mills also allowed the students to be young people. In her room, it was as possible to make mistakes, to cause disruption, to have attention deviated to other things as to talk, laugh and have fun. For every disruption or incident, she showed them she was there, paying attention to what was happening. She did not reprehend them; on the contrary, she answered with a funny expression in which she was acknowledging her presence and awareness that it was funny, but that they were still in class with a task to be performed. Once more, she was implying she cared about them, by pointing out when they were deviating from the task and that it could affect their outcomes. There was no pressure, no criticism or harsh disapproval, just a signpost. Again, students were free to go back to their tasks or not and she trusted that they would use their judgement to do the most appropriate thing. Being a teenager was part of the students' identities and the teacher showed she was aware of that and accepted that. However, as a way of reinforcing her own position as a teacher, she requested that they go back to their tasks (Youdell 2011).

Further proof of her trust and confidence in her students came when she gave them 30 more minutes to finish the task in the following class. She walked around, verified the information collected by each pair and believed it was best for them. It might be that this was not in the original plan, and she adapted it based on their outcomes. She knew they were not being lazy. They did what was possible during that lesson. It might 
be argued that the students' interest in storing the information in digital and alternative ways could have influenced the amount of time they spent on the task. However, this argument is not applicable, as three other pairs of students were copying the information onto paper and there was not enough time for them to finish the task either.

Although Miss Mills had built this collaborative and productive environment for the students, she had a very negative impression of herself. This was due to the tablet's mobile nature. She was aware they were supposed to move and because of her physical constitution, she was not able to deal with tablets the way she believed she was supposed to. Because of this, she was apologetic about the way she was using them. It sounded 'wrong' and inappropriate, which gave the impression that she was doing something contrary to what was expected. It suggested she was not capable of dealing with the tablets effectively.

Despite the fact that she believed she was not using tablets appropriately, she demonstrated that she had the pedagogical and technological skills to deal with the tablets (Vavoula et al. 2004; Koole 2009; Klopfer et al. 2002; Boticki et al. 2015; Lu et al. 2014; Gerger 2014; Danaher et al. 2009). She planned a lesson with one of the most recommended approaches of mobile learning, she enabled collaboration and respected each student's knowledge and individuality. She acted as a guide who was there to help at any point, accepting also the students' faults and mistakes. She signposted when they were supposed to go back to the tasks, without judging them. She also demonstrated that she had some knowledge about the capacities of the gadget. She might not have known how to use all the applications, but she encouraged the students to use them and share their knowledge to help other students who wanted to learn and use them. In addition, according to Vavoula et al. (2004), she was acting appropriately, as mobile learning also refers to the use of mobile technologies, not implying that students need to move to indicate their learning was mobile.

Because of the way she acted in relation to the students, they were able to construct their identities in a distinct way (Youdell 2011). First, she built a safe and cosy environment in which they would be comfortable. Then, she proposed a possible task to be carried out, in which they were treated as autonomous, independent and reasonable. She was confident of their knowledge and capacity to perform the task. It seemed she was sure about the quality of the outcome and even if it did not result in what she was expecting, she seemed to believe they would have done their best. Her trust in them made them trust in themselves, becoming confident of what they were doing and using their judgement to make decisions.

Students were allowed to be individuals performing different content searches. They also had space to be young people doing what they were expected to do: laugh, have fun and deviate their attention from the task. As they were allowed to have different pieces of knowledge for her, they allowed each other the same. They respected their different ICT skills and offered help and guidance regarding doing something different. They did not judge others for not knowing or doing something. Collaboration emerged as a natural consequence of the environment, as they could trust each other and there was no competition among them (Koole 2009).

Their ability to use the tablets was recognised and reinforced by the teacher, first, by trusting them this use, second, by planning the activity the way it was and third, by listening to their explanations of how to perform the task in a more effective way and emphasising how good it was to their peers. The ones who were not aware of these digital possibilities had the opportunity to become aware and learn it. They also had space to come up with other alternatives and use them if they wanted. The teacher approved of it. Because of this, they became enthusiastic about other possibilities. Although they lost interest when they 
noticed it would require more time, they were aware of other ways of working and skills they could develop if they wanted to.

However, a situation that was intriguing was the fact that some students did not have a Google account or an iTunes account. It is understandable that one student might have one and not the other. This is because if one has an Apple mobile phone, it is necessary to have an iTunes account to access and download different applications for the phone (or any other Apple gadget). If you have a non-Apple mobile, you have a limited number of options, of which the most common one is a phone with an Android system, which enables access to the Playstore, to download phone applications. However, if you do not have a Google account or an iTunes account, this is a curious fact, as the mobile phones that do not need these kinds of account are not smartphones, implying they are very basic models. It could raise questions as to why those students had that type of mobile phone. Would it be because they did not have the budget to buy smartphones? Would it be because they did not know how to use them? It is taken for granted the students would prefer to have the newest technological gadget, and this account could be inferring that not all students really have the newest model, independently of the reason. This fact deserves deeper investigation.

\section{Discussion and Conclusion}

Findings were consistent with the literature available about this topic in the sense that due to the use of tablets, students were able to work collaboratively, interacting with others (Koole 2009; Danaher et al. 2009), engaging in multiple tasks (Lu et al. 2014), although the teacher's physical capacity was not taken into account when the tablets and their trolley were acquired (Haßler et al. 2016).

With regards to the first research question, different emotions, feelings and affects emerged in the lesson due to the use of tablets and because of mobile learning. These emotions were smooth and positive between the teacher, the students and the tablet because the teacher and students acted in a way showing that they recognised each other as classroom and school subjects, and tablets reinforced this relationship.

Despite the fact that the teacher had negative feelings about not being physically capable of carrying the tablets, it did not impact her relationship with the students or the use of the tablet itself. It affected the way the researcher felt about the teacher's situation. In addition, the tablets were supposed to be used because it was the school's decision to acquire them and make them part of the everyday resources for teaching and learning.

Regarding the second research question, the teacher and the students influenced each other's' identity constitution. This is because the categories in which they are immersed (teacher/student) presuppose some practices (Youdell 2011). The practice in which the use of tablets happened was based in a student-centred approach that made the teacher and the students feel in specific ways. The students were considered responsible and mature enough to perform the task using the tablets, whilst the teacher was using the tablets as she was supposed to, with a proper approach according to literature. The tasks they were doing and the way they were doing made sense and reinforced their positions as teacher and students in a mobile learning environment (Youdell 2011; Butler 1999). The choice about using the tablets might have been influenced by the way the teacher was feeling, and made in an attempt to change this perspective about herself.

Based on the account, it was possible to notice how emotions and affects impacted the use of tablets and mobile learning and vice versa. Subjectivation and identity constitution 
is also influenced by all these elements, resulting in particular ways in which teachers and students might see themselves and each other (Youdell 2011). Although the teacher was negative about the fact that that lesson seemed to not be 'mobile enough', both teachers and students felt positive emotions overall. The negative emotions felt by the teacher were only felt by her, because they directly implicated her subject position as a teacher. Both positive and negative emotions influenced the way the teacher and students noticed their positions in the lesson, and ICT opened up space for the teacher-student binary to be switched, but also for other identities to emerge, for example the 'lovely lady' and the 'teenagers'.

It is not possible to say that the acquisition of the tablets and the trolley was made by the IT department only. On the other hand, it can be claimed that not all staff capacities were considered when the acquisition of tablets and trolley was made, confirming that the decision-making process does not consider all the teachers and their capacities (Haßler et al. 2016).

It is not possible to conclude whether the use of tablets improved learning. What the evidence showed was a complex and rich environment, in which many noises were made and heard, in a mix of personal, contextual and situated themes, actions, emotions and events. Tablets allowed students access to information, connectivity to different resources (if they wanted to print the information collected or send it via e-mail) and portability (not only of the tablet itself but also of the information they were collecting). It made students more flexible about which tools to use to collect and store information. The fact that the students were in Miss Mills' room acknowledged their presence and allowed them to manage the information they needed. As each student was given one gadget but they were supposed to work in pairs, their individuality had space to emerge, as each student could be responsible for developing part of the task, in the way they judged best for them. As a consequence, engagement, social interactivity and collaboration emerged naturally and increased as the lesson happened.

Considering that all these facts are recognisable as elements of mobile learning, it is possible to say that even with the lesson happening in a delimited place (Miss Mills' room), students took advantage of the learning opportunities offered by the situation as a whole. It was not the fact that the trolley with the tablets did not go to the 6th form building that prevented them from having a mobile experience. It might be argued that the learning outcomes regarding the History subject were not substantial. However, it is undeniable that there was a meaningful learning experience regarding ICT, with the purpose of accessing and storing information. In order to evaluate learning about the subject History, a longer and more detailed process would be necessary. However, ICT skills were developed in that lesson, even with the teacher not having planned that.

This study also concluded that the Education Information Communication Technology Assemblage is composed of human subjects, practices, discourses, emotions, affects, policy making, curriculum and school subjects. It is not possible to say that schooling is better due to its use. On the contrary, ICT evidenced three productive forces that demonstrated that there are issues to be resolved in education. This is because teachers and students are going to be evaluated as 'good' or 'bad' depending on the use they make of ICT. This fact is evidenced in the teacher's discourse and actions. In order to be recognised as a twenty-first century teacher, she knew she was supposed to use the tablet in specific ways. The use of ICT enabled students and teacher to become something else: she had the opportunity to be a student, by learning how to do things with the students; the students had the opportunity to be teachers, by showing each other and the teacher how to do things; the students had the opportunity to be children and play with Siri and the camera. ICT also showed that it has the force to influence the way people feel (Kraftl 2015a). The teacher and the students felt 
the way they did in the account because of ICT: students were more relaxed, the teacher was positive about what they were doing and how they were doing it. ICT also had the capacity to evidence issues related to the schooling process, which might not be caused by ICT directly. The fact that the tablets and the trolley were bought without considering the physical limitations of teachers and the building demonstrates how the decision-making process sometimes does not involve the ones directly implicated in it (Haßler et al. 2016). Findings from this study were also reiterated by the findings of the broad study (Lameu 2017).

The limitation of this study is that it is situated in place and time: basic education, in the UK, from 2014 to 2017. It might be that replication of this study will bring different results and that what was discussed here will not be applicable in different contexts. However, the insights that this replication could provide would be beneficial for discussing the use of ICT in the UK and in other parts of the world. Further research should focus on ICT topics that were not studied. It is suggested that maker spaces, virtual reality and augmented reality could provide interesting insights about the use of ICT in basic education. One last suggestion would be to develop a similar investigation in order to identify other components of the Education ICT assemblage, how it varies from context to context, and if the nature of their productive forces varies as well.

Acknowledgements The author would like to acknowledge comments and insights from Professor Deborah Youdell and Dr. Ian McGimpsey, which were essential for the development of this study. The author would also like to thank the Brazilian agency CAPES-Coordination for the Improvement of Higher Education Personnel-and the Research Grant (2909/13-8) for their financial support of this research.

Open Access This article is distributed under the terms of the Creative Commons Attribution 4.0 International License (http://creativecommons.org/licenses/by/4.0/), which permits unrestricted use, distribution, and reproduction in any medium, provided you give appropriate credit to the original author(s) and the source, provide a link to the Creative Commons license, and indicate if changes were made.

\section{References}

Bannan, B., Cook, J., \& Pachler, N. (2016). Reconceptualizing design research in the age of mobile learning. Interactive Learning Environments, 24(5), 938-953.

Blazek, M., \& Kraftl, P. (Eds.). (2015). Introduction: Children's emotions in policy and practice. In Children's emotions in policy and practice (pp. 1-13). London: Palgrave Macmillan.

Boticki, I., Baksa, J., Seow, P., \& Looi, C. K. (2015). Usage of a mobile social learning platform with virtual badges in a primary school. Computers \& Education, 86, 120-136.

Butler, J. (1997). Excitable speech: A politics of the performative. London: Psychology Press.

Butler, J. (1999). Gender trouble: Feminism and the subversion of identity. Abingdon: Routledge.

Camilleri, M. A., \& Camilleri, A. C. (2017). Digital learning resources and ubiquitous technologies in education. Technology, Knowledge and Learning, 22(1), 65-82.

Chiang, F. K., Zhu, G., Wang, Q., Cui, Z., Cai, S., \& Yu, S. (2016). Research and trends in mobile learning from 1976 to 2013: A content analysis of patents in selected databases. British Journal of Educational Technology, 47(6), 1006-1019.

Danaher, P., Gururajan, R., \& Hafeez-Baig, A. (2009). Transforming the practice of mobile learning: promoting pedagogical innovation through educational principles and strategies that work. In V. Ryu \& D. Parsons (Eds.), Innovative mobile learning: Techniques and technologies (pp. 21-46). Hershey: IGI Global. https://doi.org/10.4018/978-1-60566-062-2.ch002.

DeLanda, M. (2006). A new philosophy of society: Assemblage theory and social complexity. London: A\&C Black.

Deleuze, G., \& Guattari, F. (1984). Anti-oedipus: Capitalism and schizophrenia. London: Bloomsbury Publishing.

Deleuze, G., \& Guattari, F. (1987). A thousand plateaus: Capitalism and schizophrenia. London: Bloomsbury Publishing. 
Domingo, M. G., \& Gargante, A. B. (2016). Exploring the use of educational technology in primary education: Teachers' perception of mobile technology learning impacts and applications' use in the classroom. Computers in Human Behavior, 56, 21-28.

Foucault, M. (1982). The subject and power. Critical Inquiry, 8(4), 777-795.

Furió, D., Juan, M. C., Seguí, I., \& Vivó, R. (2015). Mobile learning vs. traditional classroom lessons: A comparative study. Journal of Computer Assisted learning, 31(3), 189-201.

Gerger, K. (2014). 1: 1 tablet technology implementation in the Manhattan Beach Unified School District: A case study. Long Beach: California State University.

Haßler, B., Major, L., \& Hennessy, S. (2016). Tablet use in schools: A critical review of the evidence for learning outcomes. Journal of Computer Assisted learning, 32(2), 139-156.

Hegelund, A. (2005). Objectivity and subjectivity in the ethnographic method. Qualitative Health Research, 15(5), 647-668.

Kearney, M., Schuck, S., Burden, K., \& Aubusson, P. (2012). Viewing mobile learning from a pedagogical perspective. Research in Learning Technology, 20, n1.

Klopfer, E., Squire, K., \& Jenkins, H. (2002). Environmental detectives: PDAs as a window into a virtual simulated world. In IEEE International workshop on wireless and mobile technologies in education, 2002. Proceedings (pp. 95-98). IEEE.

Koole, M. L. (2009). A model for framing mobile learning. In M. Ally (Ed.), Mobile learning: Transforming the delivery of education and training (pp. 25-47). Edmonton: Av Press.

Kraftl, P. (2013). Beyond 'voice', beyond 'agency', beyond 'politics'? Hybrid childhoods and some critical reflections on children's emotional geographies. Emotion, Space and Society, 9, 13-23.

Kraftl, P. (2015a). Geographies of alternative education. Bristol: Policy Press.

Kraftl, P. (2015b). Alter-childhoods: Biopolitics and childhoods in alternative education spaces. Annals of the Association of American Geographers, 105(1), 219-237.

Kraftl, P., \& Adey, P. (2008). Architecture/affect/inhabitation: Geographies of being-in buildings. Annals of the Association of American Geographers, 98(1), 213-231.

Kukulska-Hulme, A. (2005). Mobile learning: A handbook for educators and trainers. London: Psychology Press.

Lameu, P. (2017). Education ICT Assemblage: Encounters of discourses, emotions, affects, subjects, and their productive forces. Ph.D. thesis, University of Birmingham.

Lu, J., Meng, S., \& Tam, V. (2014). Learning Chinese characters via mobile technology in a primary school classroom. Educational Media International, 51(3), 166-184.

Massumi, B. (1987). Translator's foreword: Pleasures of philosophy. In G. Deleuze \& F. Guattari (Eds.), A thousand plateaus: Capitalism and schizophrenia. London: Bloomsbury Publishing.

Pachler, N., Bachmair, B., \& Cook, J. (2010). Mobile devices as resources for learning: Adoption trends, characteristics, constraints and challenges. In N. Pachler, B. Bachmair, \& J. Cook (Eds.), Mobile learning (pp. 73-93). New York: Springer.

Sharples, M., Arnedillo-Sánchez, I., Milrad, M., \& Vavoula, G. (2009). Mobile learning. In N. Balacheff, S. Ludvigsen, T. de Jong, A. Lazonder \& S. Barnes (Eds.), Technology-enhanced learning. Dordrecht: Springer.

Traxler, J. (2007). Defining, discussing and evaluating mobile learning: The moving finger writes and having writ... The International Review of Research in Open and Distributed Learning. https://doi. org/10.19173/irrodl.v8i2.346.

Traxler, J. (2009). Current state of mobile learning. In M. Ally (Ed.), Mobile learning: Transforming the delivery of education and training (Vol. 1, pp. 9-24). Athabasca: Athabasca University Press.

Vavoula, G. N., Lefrere, P., O’Malley, C., Sharples, M. \& Taylor, J. (2004). Producing guidelines for learning, teaching and tutoring in a mobile environment. In The 2nd IEEE international workshop on wireless and mobile technologies in education, 2004. Proceedings (pp. 173-176). IEEE.

Wu, W. H., Wu, Y. C. J., Chen, C. Y., Kao, H. Y., Lin, C. H., \& Huang, S. H. (2012). Review of trends from mobile learning studies: A meta-analysis. Computers \& Education, 59(2), 817-827.

Youdell, D. (2011). School trouble: Identity, power and politics in education. London: Routledge.

Youdell, D. (2015). Assemblage theory and education policy sociology. In K. Gulson, M. Clarke, \& E. B. Petersen (Eds.), Education policy and contemporary theory: Implications for research (pp. 110-121). London: Routledge.

Youdell, D., \& McGimpsey, I. (2015). Assembling, disassembling and reassembling 'youth services' in Austerity Britain. Critical Studies in Education, 56(1), 116-130.

Publisher's Note Springer Nature remains neutral with regard to jurisdictional claims in published maps and institutional affiliations. 